\title{
Parental expectations of maternal and child health services
}

\begin{abstract}
This article reports on a survey research $(\mathrm{N}=1418)$ aimed at examining whether parental expectations of maternal and child health $(\mathrm{MCH})$ services are influenced by group characteristics (e.g. SES, ethnicity, at-risk-of-poverty) and/or individual parenting context variables (e.g. received social support) in a context where these services are available to all. The findings reveal that parents have different expectations about the technical and relational expertise of $\mathrm{MCH}$ nurses. However, we found only very weak associations between family characteristics and parental expectations, suggesting that individual differences matter more than SES and other more traditional distinctions. Implications for MCH services are made.
\end{abstract}

\section{Key words}

Maternal and child health service, at-risk parents, survey research, nursing, support 


\section{Introduction}

Health professionals have a distinguished history of providing care for all who need it (Cronenwett, Grey, McCaluley, Meleis, \& Salmon, 2011). Traditionally, health professionals have valued care that incorporates individuals' unique characteristics, including their beliefs, disease states, cognition levels, ethnicities, needs, preferences and resources (Beck et al., 2010). Individualized or tailored care is preferred to standardized care both by nurses and individuals (Grace \& Powers, 2009) as reallocating work in more client-centered ways appears to increase job satisfaction and job retention (Morgan \& Lynn, 2009) as well as improve care outcomes (Mitchell, 2008).

Also within the maternal and child health $(\mathrm{MCH})$ literature the importance of determining the aspects that could contribute to parents' satisfaction with $\mathrm{MCH}$ care is recognized (Camacho et al., 2012; DeCamp et al., 2013; Fägerskiöld, Wahlberg, \& Eka, 2001; Fägerskiöld, Timpka, \& Ek, 2003; Humbert \& Roberts, 2009). As the focus of MCH care "has changed from the child's growth and development to the psychosocial health of the whole family" and "to working in partnership with families to find solutions to their problems" (Eronen, Pincombe, \& Calabretto, 2010, p. 132) more insight in parents' contexts, motives, needs or expectations offers a vital source of information to improve the delivery of $\mathrm{MCH}$ care. However, "the voices, perspectives, and experiences of pregnant and parenting women are [...] often overlooked or not understood by professionals" (Humbert \& Roberts, 2009, p. 588). In addition, studies on maternal and child health care tend to focus on specific programs for specific target groups such as home visiting programs which are generally considered a promising strategy for at-risk families, such as single parents, low-income families, teenage mothers or parents from ethnic minorities (McCabe, Potash, Omohundro, \& Taylor, 2012; McNaughton, 2004; Meghea, Zhu, Lindsay, Moore, \& Roman, 2012; Peacock, Konrad, Watson, Nickel, \& Muhajarine, 2013; Sheppard, Williams, \& 
Richardson, 2005). Studies that go beyond targeted at-risk groups seem to be rather scarce. Researchers have only recently begun survey research on larger cohorts looking at individuals' assessment of health care (Haggerty et al., 2010). As a result we still lack empirical evidence on how parental expectations may vary across different groups and therefore also on how MCH care delivery should or should not be differentially shaped for specific groups.

This article reports the findings of a survey research conducted with parents on their expectations of staff working in MCH centers of 'Kind en Gezin' (Child and Family) in Flanders, the Dutchspeaking part of Belgium. 'Child and Family' is a governmental agency that works actively in the policy area of 'Public Health, Welfare and Family' in the Flemish region of Belgium, counting about 70,000 births per year (Child and Family, 2010). It focuses on preventive treatment and guidance of young children and is responsible for the optimal support for parents-to-be and parents with young children. All its services are free of charge for all parents of children between 0 and 3 years old. Child and Family offers information sessions for parents-to-be in conjunction with maternity hospitals, introductory visits to the maternity ward, home visits (at least two) by the regional $\mathrm{MCH}$ nurse, a hearing test during the first week of life, information through website and brochures, advice through the Child and Family telephone support line and 10 consultations at one of the 342 regional MCH centers between 4 weeks and 30 months after childbirth. In the $\mathrm{MCH}$ centers, a volunteer who weighs and measures the child welcomes the parents. After this, the parents have a conversation with the regional $\mathrm{MCH}$ nurse to discuss their child's development. Then a physician checks the child's health and development and gives the necessary vaccinations if the parents wish so.

Child and Family offers an interesting research setting to research parental expectations due to its universal approach to preventive health care for all infants and their parents. Data from the Child 
and Family database shows that its services are highly-used: $91.9 \%$ of all new mothers in Flanders receive an introductory visit and during the first three months after childbirth, $97.3 \%$ of the parents receive at least one home visit by the $\mathrm{MCH}$ nurse, sometimes accompanied by a social worker. $88.3 \%$ make use of the $\mathrm{MCH}$ centers; $94.7 \%$ of all newborns received a hearing test at one of the MCH centers and at 18 months after childbirth, two out of three infants have received all vaccinations at the $\mathrm{MCH}$ center. In short, the $\mathrm{MCH}$ centers of Child and Family reach a broad range of parents and therefore allows studying parental expectations of MCHNs in a very diverse, rather than targeted, sample.

The main aim of the present study focused on the nurses' work within the MCH centers and aimed at examining whether parental expectations of the nurses working in these centers are influenced by group characteristics (socio-economic status, ethnicity of the mother, at-risk-ofpoverty and family composition) and/or individual parenting context variables (e.g., worries about the child, received social support, the need to meet other parents, etc.).

\section{Methods}

\section{Design and sample}

The findings reported here are derived from a larger study conducted between August 2009 and December 2010 by order of Child and Family. The study wished to investigate expectations and preferences of parents with regard to the preventive health care of their children (aged 0 to 3 years old) and to examine to what extent differences in parental expectations were molded by demographic and family characteristics. The data were collected through a postal and face-to-face survey from a representative sample of parents, randomly selected from the Child and Family database. The postal survey was sent to a sample of 3,200 families randomly selected from all 
Dutch-speaking families which were included in the Child and Family database and which had a newborn between 1 February 2006 and 30 November 2009. 1,219 parents filled in the postal survey (38.1\%). However, as Child and Family wanted to ensure sufficient participation of vulnerable families, an additional sample of 530 families living in poverty and/or ethnic minority families was also selected from the Child and Family database. Ethnicity was defined as the nationality of the mother at childbirth. Due to financial and practical reasons, the second sample included only parents who communicate with the Child \& Family staff members in Dutch, French, English or Turkish and who lived in one of the eight pre-selected areas (both rural and urban) in Flanders. Families were contacted by trained bilingual and ethnic minority interviewers for a face-to-face interview in their home using a French/English/Turkish/Dutch version of the postal survey. The aim was to contact families until 150 interviews were conducted. As each interviewer had to finish his contacts after the number of 150 interviews was reached, we were able to realize more interviews than we had initially planned, namely 199 interviews.

Completion and return of the survey was considered implied consent. Though we recognize that the use of different methods of data collection (postal and face-to-face) can have an effect on the measurement outcome, our mixed-mode design was both intentional and practical. We believe that for families living in poverty social verbal communication is the most appropriate choice in terms of media familiarity as compared to postal surveys. However, administering all responses through face-to-face interviews, and thus avoiding mode effects, was impossible both practically and financially.

The final dataset comprised of 1,418 respondents. Table 1 gives an overview of the main characteristics of the sample. 
Table 1

Sample description of the parents $(N=1,418)$

\begin{tabular}{|c|c|c|}
\hline \multicolumn{3}{|l|}{ Family composition } \\
\hline Single parents $(\%)$ & \multicolumn{2}{|l|}{6.1} \\
\hline Two parent family (\%) & \multicolumn{2}{|l|}{93.9} \\
\hline \multicolumn{3}{|l|}{ Problem child } \\
\hline No $(\%)$ & \multicolumn{2}{|l|}{89.1} \\
\hline Yes $(\%)$ & \multicolumn{2}{|l|}{10.9} \\
\hline \multicolumn{3}{|l|}{ First-time parent } \\
\hline Yes $(\%)$ & \multicolumn{2}{|l|}{46.1} \\
\hline No $(\%)$ & \multicolumn{2}{|l|}{53.9} \\
\hline \multicolumn{3}{|l|}{ Ethnicity of the mother } \\
\hline Belgian (\%) & \multicolumn{2}{|l|}{78.8} \\
\hline European $(\%)$ & \multicolumn{2}{|l|}{3.7} \\
\hline Non-European $(\%)$ & \multicolumn{2}{|l|}{17.6} \\
\hline Diploma parent & Respondent & Partner \\
\hline Primary education or none $(\%)$ & 9.3 & 6.8 \\
\hline Secondary education $(\%)$ & 30.8 & 41.4 \\
\hline College/university (\%) & 54.4 & 42.2 \\
\hline Other $(\%)$ & 5.5 & 3.1 \\
\hline Not applicable $(\%)$ & - & 6.4 \\
\hline Employment & Respondent & Partner \\
\hline Employed (\%) & 63.8 & 83.6 \\
\hline Employment temporarily interrupted (\%) & 15.4 & 2.5 \\
\hline Unemployed (\%) & 19.2 & 6.5 \\
\hline Other $(\%)$ & 1.6 & 1.0 \\
\hline Not applicable (\%) & - & 6.4 \\
\hline \multicolumn{3}{|l|}{ At-risk-of-poverty } \\
\hline Under poverty threshold (\%) & \multicolumn{2}{|l|}{13.6} \\
\hline Around poverty threshold (\%) & \multicolumn{2}{|l|}{9.8} \\
\hline Above poverty threshold (\%) & \multicolumn{2}{|l|}{76.6} \\
\hline
\end{tabular}


The representativeness of this dataset was checked against the population (i.e. all children born in Flanders between 1 February 2006 and 30 November 2009). As was expected, our sample was not representative with regard to poverty and ethnicity with poor families being overrepresented and ethnic minority families still being underrepresented. To correct these biases, sampling weights were applied to each respondent in our database.

\section{Measures}

To devise the questionnaire, the study was preceded by a qualitative study in which 37 stakeholders (MCHNs, physicians, social workers and parents) were interviewed using the critical incident technique (Flanagan, 1954; Gremler, 2004). The transcripts of the interviews were analyzed using the thematic analysis of Smith (1995). Based on these findings, together with literature from previous research (Hedebouw \& Peetermans, 2009; Rullo \& Musatti, 2005; Seghers, 1995; Vandenbroeck, Boonaert, Van der Mespel, \& De Brabandere, 2009), we derived the main themes of our survey. In this article we focus on the part about parental expectations of the MCHNs.

Based on the data gathered by the questionnaire, we first constructed three group characteristics, considered as independent variables: family composition (indicating whether the respondent is a single-parent or not); Socio-economic status (SES) was constructed using the $z$ scores of seven variables: monthly family income, educational degree, profession and labor situation of the respondent and educational degree, profession and labor situation of his/her partner (Reynders, Nicaise, \& Vandamme, 2005). The higher the score, the higher the respondents' SES. At-risk-of-poverty (categorized as under, around or above the personalized poverty threshold) was constructed using the variable monthly family income (10 categories, going from less than 700 euro to 5000 euro or more) and based on the European Statistics on 
Income and Living Conditions (Atkinson \& Marlier, 2010). A fourth variable, ethnicity of the mother is based on the nationality of the mother at childbirth and was categorized as Belgian, European (i.e. EU-25 countries) and non-European (labeled as ethnic minority families). This variable was derived from information that was available in the Child and Family database and which was merged with our own dataset using the unique ID number of the parent.

Second, the data obtained by the questionnaire were also used to construct a series of individual parenting context variables. First, the variable problem child (categorized in 'yes' or 'no') indicates whether, according to the respondent, the child has been diagnosed with a problem (either health, developmental or educational) or not. Second, we also asked whether the respondent was a first-time parent or not (dichotomized as 'yes' or 'no'). Third, the respondents had to evaluate on a 5-point Likert scale whether they worried about several aspects of their child's development or about themselves. Based on these answers we constructed three variables, namely worries about the child's physical development (6 items, e.g. 'I worry about the growth of my child', Cronbach's $\alpha=.82$ ), worries about the child's psycho-social development (5 itmes, e.g. 'I worry about the emotional development of my baby', Cronbach's $\alpha=.80$ ) as well as worries about the parents' own situation (4 items, e.g. 'I worry about my financial situation, Cronbach's $\alpha=.71)$. Fourth, the variable time alone with the child refers to the average number of hours the parent spend alone with his/her child(ren) during the day. The variable trouble being alone with the child expresses the extent to which the parent agreed that being alone with his/her child is a burden as evaluated on a 5-point Likert scale from 1 ('totally not agree') to 5 ('totally agree')). Finally, we included different variables that referred to parents' social support and which all had to be evaluated on a 5-point Likert scale: the variable contact with parents gave account of how often parents met other parents with young children. The variable need to meet 
with other parents is the respondent's score on the item 'I feel the need to meet other parents of young children more often'. Lastly, the respondents had to evaluate for each of the 10 listed potential (in)formal sources of support (such as partner, family, professional help) to what extent they believed that these persons/services would offer them practical, emotional and information support if they needed it (going from ' 1 ' never to ' 5 ' very often). Based on the scores on these questions we constructed the variables perceived practical support (Cronbach's $\alpha=.84$ ); perceived emotional support (Cronbach's $\alpha=.85$ ); and perceived informational support (Cronbach's $\alpha=.84$ ).

The outcome variables used in this study are the expectations about the $\mathrm{MCH}$ nurses (MCHN). The respondents had to evaluate fifteen items about the nurses on a five-point Likert scale, varying from 1 ('totally not important') to 5 ('very important'). The items reflected several aspects of the work of the MCHN, e.g. 'I find it important that the MCHN has medical expertise', 'I find it important that the MCHN can give me advice on how to deal with my child' or 'takes enough time to talk to me'. Based on the responses, these 15 items were reduced to seven variables: informative support (4 items: knowledgeable, advice about infant care, educational advice, explanations: Cronbach's $\alpha=.83$ ); emotional support (2 items: assurance, confirmation: Cronbach's $\alpha=.80$ ); social support (2 items: taking time, chatting: Cronbach's $\alpha=.80$ ); accessibility (2 items: MCHN knows us well, is reachable: Cronbach's $\alpha=.75$ ); respect ( 3 items: pleasant contact with child, respectful contact with parent, respect for privacy: Cronbach's $\alpha=$ .74); efficiency and continuity (both single items).

\section{Analytic strategy}


For each of the seven outcome variables multiple regression analysis was used with the group characteristics and individual parenting context variables as independent variables. The independent variables were added in two separate blocks: block 1 consisted of the group characteristics and block 2 consisted of the individual parenting context variables. This allowed analyzing how much of the variance in parental expectations was explained by adding the individual parenting context variables to the group characteristics. The data were performed using the Statistical Package for the Social Sciences (SPSS 19). Missing data were deleted listwise, meaning that if any of the variables included in the model has a missing value the entire case is excluded from the analysis. The level of significance was set to $\alpha=.05$.

\section{Results}

The findings show that parents have high expectations about MCHNs. Over $84 \%$ of the parents agreed that they expect the MCHNs to give them informative support $(M=4.33 ; S D=0.73)$ and to be efficient $(M=4.22 ; S D=0.88)$. Also emotional support was highly valued by $84 \%$ of the parents $(M=4.25 ; S D=0.81)$. The frequencies showed slightly more variation about expectations with regard to relational aspects: only 53\% of the parents agreed that they expect social support $(M=3.74 ; S D=0.85)$ and accessibility $(M=3.72 ; S D=0.91)$ from the MCHNs.

To further analyze the variance in parents' expectations of the MCHNs, we first composed for each of our seven outcome variables a multiple regression model with the group characteristics (SES, family composition, ethnicity of the mother and at-risk-of-poverty) as independent variables. As the results in Table 2 show, all seven models are significant. 
Table 2

Expectations of the MCH: unstandardized B-coefficients from the multiple regression analyses with the group characteristics

\begin{tabular}{|c|c|c|c|c|c|c|c|}
\hline & $\begin{array}{l}\text { Informative } \\
\text { support }\end{array}$ & $\begin{array}{l}\text { Emotional } \\
\text { support }\end{array}$ & $\begin{array}{l}\text { Social } \\
\text { support }\end{array}$ & Efficiency & Accessibility & Respect & Continuity \\
\hline SES & -.051 & $-.278 * * *$ & $-.472 * * *$ & -.050 & $-.594 * * *$ & $-.349 * *$ & $-.250 * * *$ \\
\hline $\begin{array}{l}\text { Family composition } \\
\text { (ref: single parents) }\end{array}$ & $.805^{*}$ & .309 & .263 & $.221 *$ & .289 & $.842 * *$ & .015 \\
\hline \multicolumn{7}{|l|}{ (ref: Belgian mothers) } & \\
\hline non-European mothers & .295 & -.072 & $.566 * * *$ & -.001 & $.443 * *$ & .003 & $-.282 * *$ \\
\hline European mothers & .484 & .128 & .226 & -.157 & .393 & .066 & .086 \\
\hline \multicolumn{8}{|l|}{ At-risk-of-poverty } \\
\hline (ref: above poverty threshold) & & & & & & & \\
\hline Under poverty threshold & -.248 & -.255 & $-.412 *$ & -.163 & $-.438 *$ & .032 & $-.298 *$ \\
\hline Around poverty threshold & $-.591 *$ & $-.348 *$ & -.191 & $-.236 * *$ & $-.486 *$ & -.286 & -.229 \\
\hline Adjusted $R^{2}$ & $.007 *$ & $.008^{*}$ & $.061 * * *$ & $.008 * *$ & $.061 * * *$ & $.017 * * *$ & $.017 * * *$ \\
\hline
\end{tabular}

$* p<.05 ; * * p<.01 ; * * * p<.001$.

SES appears to be the strongest significant predictor in five of the seven models. Parents with a lower SES attach more importance to emotional support, social support, accessibility, respect and continuity than parents with a higher SES. Two parent families consider informative support, efficiency and respect slightly more important than single parents. Non-European mothers value social support and accessibility more than Belgian and European mothers, but attach less importance to continuity. Parents with a monthly family income under the personalized poverty threshold consider social support, accessibility and continuity slightly less important than parents above the poverty threshold. For parents with a monthly family income around the personalized poverty threshold informative support, emotional support, efficiency and accessibility count slightly less than for parents above the personalized poverty threshold. 
However, the values of the adjusted $R^{2}$ in Table 2 show that all models only have a very small predictive value ranging from $0.7 \%$ (informative support) to $6.1 \%$ (social support and accessibility). Consequently only $0.7 \%$ to $6.1 \%$ of the variances in the scores on the expectations of the MCHN can be explained by the group characteristics of the parents. Or, put differently, there are only weak associations between the parental expectations of the MCHN and their sociodemographic background in terms of SES, ethnicity, single parent or not, and at-risk-of-poverty or not.

In order to examine whether parental expectations are better explained by individual characteristics, we added the individual parenting contexts variables to our models. The results are presented in Table 3.

Table 3

Expectations of the MCH: unstandardized B-coefficients from the multiple regression analyses with the group characteristics and the individual parenting context variables

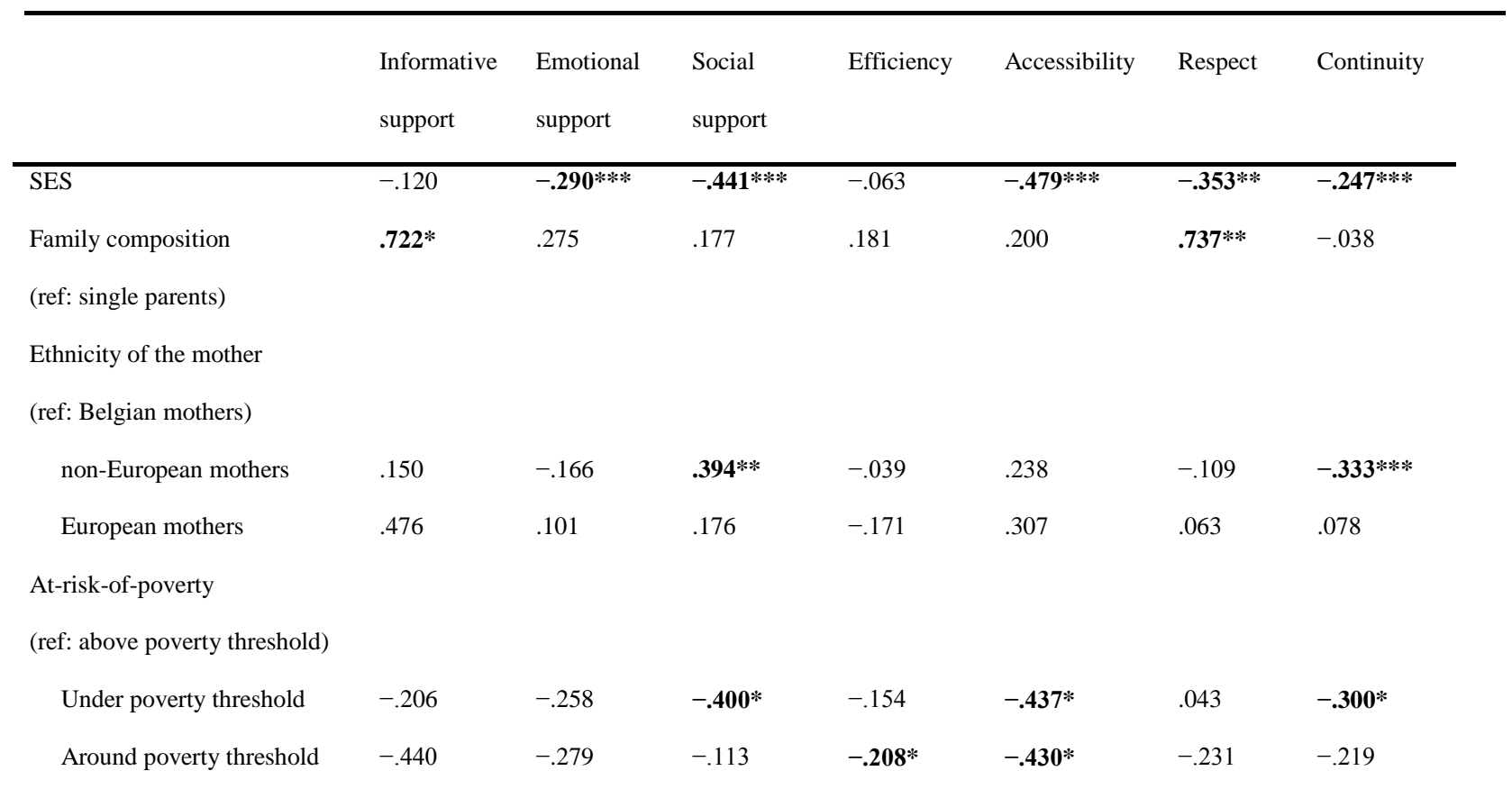




\begin{tabular}{|c|c|c|c|c|c|c|c|}
\hline First-time parent (ref: yes) & -.065 & .055 & .094 & .008 & .130 & .033 & .061 \\
\hline $\begin{array}{l}\text { Problem child } \\
\text { (ref: no) }\end{array}$ & -.007 & -.114 & .140 & -.021 & .111 & .205 & .093 \\
\hline Time alone with child & -.001 & .002 & .014 & .003 & .019 & .014 & .006 \\
\hline Trouble being alone with child & -.012 & -.008 & -.037 & -.017 & -.056 & -.110 & -.043 \\
\hline Need to meet other parents & $.270 * * *$ & $.162^{* * *}$ & $.147 * *$ & .036 & $.129 * *$ & $.115^{*}$ & .040 \\
\hline Worries about physical dev. & -.025 & $-.031 *$ & .000 & -.010 & .007 & -.016 & -.002 \\
\hline $\begin{array}{l}\text { Worries about psycho-social } \\
\text { dev. }\end{array}$ & -.003 & -.007 & -.019 & -.005 & $-.049 * *$ & -.022 & -.011 \\
\hline Worries about own situation & -.024 & .005 & -.005 & -.003 & .011 & -.007 & -.005 \\
\hline Contact with parents & .005 & -.002 & .003 & -.007 & .003 & -.011 & .003 \\
\hline Perceived practical support & $-.040^{* *}$ & $-.021 *$ & -.008 & -.008 & .012 & $-.031^{* *}$ & -.008 \\
\hline Perceived emotional support & .023 & $.029 * *$ & $.042 * * *$ & .009 & $.050 * * *$ & $.056 * * *$ & $.019 * *$ \\
\hline Perceived informative support & $.056 * *$ & .013 & .002 & $.011 *$ & $-.028 * *$ & .003 & .000 \\
\hline Adjusted $R^{2}$ & $.042 * * *$ & $.046 * * *$ & $.113 * * *$ & $.035 * * *$ & $.114 * * *$ & $.051 * * *$ & $.029 * *$ \\
\hline
\end{tabular}

$* p<.05 ; * * p<.01 ; * * * p<.001$

All models are significant at a significance level of 0.01 . The results in Table 3 show that several individual parenting context variables are not significant predictors of parental expectations of the MCHN. The extent to which parents have a child diagnosed with a problem, spend time alone with their child(ren), have trouble being alone with their child, have few contacts with other parents and worry about their own situation or the fact that they are a first-time parent or not do not appear to have a significant influence on parents' need for support from the MCHNs. Neither do these factors have an influence on the importance they attach to efficiency, accessibility, respect and continuity. However, parents' need to meet other parents is significant in five models, especially in parents' need for support: the more parents wish to meet other parents more often, the more they expect informative, emotional and social support from the MCHNs. Also parents' perceived social support, especially emotional support, significantly influences their expectations of the MCHNs. 
Again, however, we observe that the models with the individual parenting context variables hardly account for the variances in responses of the parents. The adjusted $R^{2}$ varies from $2.9 \%$ (continuity) to $11.4 \%$ (accessibility). Consequently, parental expectations of the MCHN seem to be only weakly predicted by the contexts in which parents have to raise their children.

\section{Discussion}

We started this article with the observation that we need more insight in parents' contexts, motives, needs or expectations about $\mathrm{MCH}$ care. Such insight is important in order to install a good relationship between the parents and nurse, which is considered an important prerequisite for MCHNs to be able to support parents in their (new) role (Fägerskiöld \& Ek, 2003). The study reported in this article asked 1418 parents from diverse socio-economic backgrounds about their expectations of the MCHNs. Even though our research was both exploratory and limited to the context of Flanders, our study raised important issues that can be of interest for $\mathrm{MCH}$ practice and education in other contexts.

Our research showed that there was a strong agreement among parents from diverse sociodemographic backgrounds about the expertise and informational aspects of the MCHN's tasks. Our study confirmed previous research (Camacho et al., 2012; Fägerskiöld et al., 2001; Fägerskiöld et al., 2003) that suggested that parents expect MCHNs to be knowledgeable and to provide them with sound advice about how to deal with or take care of their child (e.g. food, sleep). The fact that being a first-time parent was not a significant predictor in our models shows that getting professional advice from the MCHN remains an important aspect for parents, even if they already have experience in caring for a newborn. 
Our results revealed fewer consensuses, though, about the importance of relational aspects of the MCHN's work. While some parents gave high scores for social conversations, continuity and accessibility, other parents seemed to attach less importance to these relational aspects. These findings suggest that parents might have different expectations about how the professional support and advice is organized and expressed. However, in contrast to some previous studies (Sargent, 2009), the differences between parental expectations about the MCHN's relational approach seemed to be rather unpredictable in our study as neither group characteristics nor individual parenting context variables sufficed to predict parental expectations. This suggests that client-centered $\mathrm{MCH}$ care cannot be constructed along traditional socio-demographic variables that frame at-risk parents (such as low income, ethnic background or single parents), as Beck et al. (2010) hoped. This implies that at-risk parents do not necessarily have different expectations of MCHN than non-at-risk parents and vice versa. This is an important finding, given the recent service climate in which funds are increasingly allocated to targeted, population-based programs (Rowe \& Barnes, 2006, p. 22). As a result, MCHN staff will need to invest in the individual needs of parents and adapt their approach time and again to these differential, yet unpredictable expectations. For the education of MCHNs all this implies that interpersonal skills should be at the core of the curriculum. As Fägerskiöld and Ek (2003, p. 126) stressed it is important for MCHNs to learn to reflect upon parents' expectations in order to fulfill them.

\section{References}

Atkinson, A. B., \& Marlier, E. (Eds.). (2010). Income and living conditions in Europe. Luxembourg: Publication Office of the European Union.

Beck, C., McSweeney, J., Richards, K., Robertson, P., Tsai, P. F., \& Souder, E. (2010). Challenges in tailored intervention research. Nursing Outlook, 58, 104-110. 
Camacho, F. T., Weisman, C. S., Anderson, R. T., Hillemeier, M. M., Schaefer, E. W., \& Paul, I. M. (2012). Development and validation of a scale measuring satisfaction with maternal and newborn health care following childbirth. Maternal and Child Health Journal, 16, 997-1007.

Cronenwett, L., Grey, M., McCauley, L., Meleis, A., \& Salmon M. (2011). The doctor of nursing practice: A national workforce perspective. Nursing Outlook, 59, 9-17.

DeCamp, L. R., Kieffer, E., Zickafoose, J. S., DeMonner, S., Valbuena, F., Davis, M. M., \& Heisler, M. (2013). The voices of limited English proficiency Latina mothers on pediatric primary care: lessons for the medical home. Maternal and Child Health Journal, 17, 95109.

Eronen, R., Pincombe, J. \& Calabretto, H. (2010). The role of child health nurses in supporting parents of young infants. Collegian, 17, 131-141.

Fägerskiöld, A., \& Ek, A. C. (2003). Expectations of the child health nurse in Sweden: two perspectives. International Nursing Review, 50, 119-128.

Fägerskiöld, A., Timpka, T., \& Ek, A. C. (2003). The view of the child health nurse among mothers. Scandinavian Journal of Caring Science, 17, 160-168.

Fägerskiöld, A., Wahlberg, V., \& Ek, A. C. (2001). Maternal expectations of the child health nurse. Nursing and Health Sciences, 3, 139-147.

Flanagan, J. C. (1954). The critical incident technique. Psychological Bulletin, 51, 327-358.

Grace, J. T., \& Powers, B. A. (2009). Claiming our core: Appraising qualitative evidence for nursing questions about human response and meaning. Nursing Outlook, 57, 27-34.

Gremler, D. D. (2004). The critical incident technique in service research. Journal of Service Research, 7, 65-89. 
Haggerty, J., Fortin, M., Beaulieu, M. D., Hudon, C., Loignon, C., Préville, M., \& Roberge, D. (2010). At the interface of community and healthcare systems: A longitudinal cohort study on evolving health and the impact of primary healthcare from the patient's perspective. BMC Health Services Research, 10, 1-10.

Hedebouw, G., \& Peetermans, A. (2009). Het gebruik van opvang voor kinderen jonger dan 3 jaar in het Vlaams Gewest. Leuven, Belgium: Steunpunt Welzijn, Volksgezondheid en Gezin.

Humbert, L. \& Roberts, T. L. (2009). The value of a learner's stance: lessons learned from pregnant and parenting women. Maternal and Child Health Journal, 13, 588-596.

Kind en Gezin (Child and Family). (2010). Jaarverslag 2009 (Annual report 2009). Brussels, Belgium: Kind en Gezin.

McCabe, B. K., Potash, D., Omohundro, E., \& Taylor, C. R. (2012). Design and implementation of an integrated, continuous evaluation, and quality improvement system for a state-based home-visiting program. Maternal and Child Health Journal, 16, 1385-1400.

McNaughton, D. B. (2004). Nurse home visits to maternal-child clients: A review of intervention research. Public Health Nursing, 21, 207-219.

Meghea, C. I., Zhu, L. Q., Lindsay, J. K., Moore, J. S., \& Roman, L. A. (2012). Infant health effects of a nurse-community health worker home visitation programme: a randomized controlled trial. Child: care, health and development, 39, 27-35.

Mitchell, P. H. (2008). Patient-centered care - A new focus on a time-honored concept. Nursing Outlook, 56, 197-198.

Morgan, J. C., \& Lynn, M. R. (2009). Satisfaction in nursing in the context of shortage. Journal of Nursing Management, 17, 401-410. 
Peacock, S., Konrad, S., Watson, E., Nickel, D., \& Muhajarine, N. (2013). Effectiveness of home visiting programs on child outcomes: a systemic review. BMC Public Health, 13, 17. doi:10.1186/1471-2458-13-17

Reynders, T., Nicaise, I., \& Vandamme, J. (2005). De constructie van een SES-variabele voor het SiBO-onderzoek. Leuven, Belgium: SiBO.

Rowe, J. \& Barnes, M. (2006). The role of child health nurses in enhancing mothering knowhow. Collegian, 13, 22-26.

Rullo, G., \& Musatti, T. (2005). Mothering young children: Child care, stress and social life. European Journal of Psychology of Education, 20, 107-119.

Sargent, A. N. (2009). Predictors of needs in mothers with infants in the neonatal intensive care unit. Journal of Reproductive and Infant Psychology, 27, 195-205.

Seghers, N. (1995). Kleine baasjes worden groot. Onderzoek naar het consumptiegedrag en het behoeftenpatroon van gezinnen met jonge kinderen inzake preventieve kinderzorg. Leuven, Belgium: HIVA.

Sheppard, V. B., Williams, K. P., \& Richardson, J. T. (2005). Women's priorities for lay health home visitors: implications for eliminating health disparities among underserved women. Journal of Health Social Policy, 18,19-35.

Smith, J. A. (1995). Semi-structured interviewing and qualitative analysis. In J. A. Smith, R. Harre, \& L. Van Langenhove (Eds.), Rethinking methods in psychology (pp. 9-26). London, UK: Sage Publications.

Vandenbroeck, M., Boonaert, T., Van der Mespel, S., \& De Brabandere, K. (2009). Dialogical spaces to reconceptualize parent support in the social investment state. Contemporary Issues in Early Childhood, 10, 66-77. 